\title{
DESIGN AND ANALYSIS OF CFD GEOMETRY CONFIGURATION CANTED WINGLET TOWARD AERODYNAMIC CHARACTERISTIC ON WING PROFIL OF THE UAV LSU-05
}

\author{
Nurul Anwar', Lazuardy Rahendra $\mathbf{P}^{2}$, Bangga Dirgantara $\mathrm{A}^{\mathbf{3}}$ \\ 1,2,3 Jurusan Teknik Dirgantara, Sekolah Tinggi Teknologi Adisutjipto Yogyakarta \\ nururlanwar9797@gmail.com@mail.com, lazuardyrp@itda.ac.id, \\ banggadirgantara@itda.ac.id
}

\begin{abstract}
Abstrct
Wing is part of an aircraft or UAV which has a function as a major component of producing lift, therefore if a problem occurs such as a vortex at the end of the wing it will affect its performance capability. This study aims to determine the condition of the air flow, the value of induced drag, and the selection of the design of the wing tip devices on the wing profile of the UAV LSU-05. The method used is numerical or computational methods with CFD-based software to predict the aerodynamic characteristics and phenomenon of airflow around the wing with wing tip devices and without it. The model used in this study is a half-wing LSU-05 with NACA 4415 made with CATIA V5R20 software and the simulation uses ANSYS CFX 17.1. Based on the previous simulation results, it was found that the application of the canted winglet geometry to the wing profile of the UAV LSU-05 affects the coefficient lift $\left(C_{L}\right) /$ coefficient drag $\left(C_{D}\right)$ value and induced drag. Whereas the coefficient lift $\left(C_{L}\right) /$ coefficient drag $\left(C_{D}\right)$ value before using the canted winglet was 18.904 after application, increased to 21.616, this causes the induced drag value change inversely with the coefficient lift $\left(C_{L}\right) /$ coefficient drag $\left(C_{D}\right)$ value where the value before application was $30.4181 \mathrm{~N}$ to $29.0566 \mathrm{~N}$.
\end{abstract}

Keywords: Canted Winglet, CFD, Wing

\section{Latar Belakang}

Wing adalah bagian pesawat atau UAV yang memiliki fungsi sebagai komponen utama penghasil gaya angkat. Wing dapat menghasilkan gaya angkat diperoleh dari perbedaan tekanan antara bagian bawah yang lebih besar sedangkan diatas lebih kecil. Tekanan yang lebih besar akan mengalir pada bagian bawah wing menuju wing tip dan menggantikan tekanan yang kecil dibagian atasnya, fenomena tersebut menghasilkan vortex yang dapat mempengaruhi performa aerodinamika yang disebut sebagai induced drag. Vortex atau pusaran aliran udara memiliki energi kinetik rotasi dan translasi yang cukup besar. Hal tersebut mengurangi efektifitas angle of attack sehingga gaya angkat yang dihasilkan juga akan berkurang. Pada penelitian sebelumnya yang dilakukan oleh A. Romadhon dan D. Herdiana dengan judul "Analisis CFD Karakteristik Aerodinamika Pada Sayap Pesawat LSU-05 Dengan Penambahan Vortex Generator". Penelitian tersebut membahas mengenai pengaruh pengaplikasian vortex generator pada konfigurasi wing UAV LSU-05 terhadap karakteristik aerodinamikanya. Namun, pada bagian wing tip UAV LSU-05 masih terjadi fenomena induced drag 1].

Berdasarkan uraian di atas untuk mengurangi induced drag dan meningkatkan performa aerodinamika wing UAV LSU-05. Maka penelitian ini akan membahas mengenai pengaruh geometri canted winglet pada profil wing UAV LSU-05 dengan tujuan untuk mengetahui fenomena aliran udara pada profil wing dan nilai induced dragnya dengan pendekatan computational fluid dynamic. Gaya aerodinamika adalah gaya yang timbul karena adanya gesekan aliran udara dengan permukaan wing yang menimbulkan perbedaan tekanan antara bagian lower surface dan upper surface. Komponen gaya aerodinamika dibagi menjadi dua 
yaitu searah dengan aliran udara disebut dengan gaya hambat (drag force) dan tegak lurus terhadap arah aliran udaranya disebut dengan gaya angkat (lift force) [2] [3].

Lift atau gaya angkat dihasilkan oleh sayap karena bentuk airfoil pada wing pesawat. Bentuk melengkung di bagian atas permukaan dan hampir datar di bagian bawah permukaan. Keadaan tersebut mengakibatkan udara yang mengalir di bagian atas permukaan sayap lebih cepat dibandingkan permukaan bawah. Dari perbedaan tersebut kecepatan yang mengakibatkan perbedaan tekanan antara bagian atas dan bawah wing, sehingga menghasilkan gaya angkat pada wing [4]. Lift atau gaya angkat dapat dirumuskan sebagai berikut:

$$
L=\frac{1}{2} \times \rho \times \mathrm{v}^{2} \times S \times C L
$$

Dimana:

$p:$ Kerapatan Udara $\left(\mathrm{kg} / \mathrm{m}^{3}\right)$

$\mathrm{v}: \operatorname{kecepatan}(\mathrm{m} / \mathrm{s})$

$\mathrm{S}$ : luas surface $\left(\mathrm{m}^{2}\right)$

$\mathrm{C}_{\mathrm{L}}$ : coefisien lift

Drag atau gaya hambat adalah gaya yang menahan laju sebuah benda bergerak atau diam dan arahnya berlawanan dengan vektor kecepatan dari arah gerak pesawat.

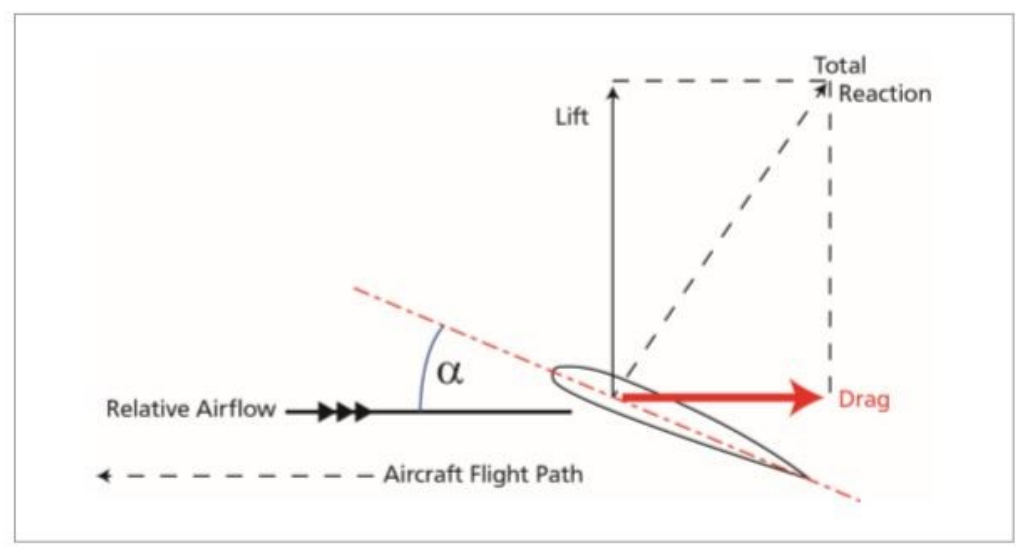

Gambar 1. Vektor Drag

Gaya ini terbagi menjadi dua bagian utama, parasite drag dan induced drag masing masing menyumbang sebesar $80 \%$. Induced drag dihasilkan sebagai akibat produksi lift sedangkan parasite drag adalah drag dari fuselage, landing gear, struts, dan permukaan lainnya yang terkena aliran udara [5]. Adapun rumus untuk mencari nilai drag sebagai berikut:

$$
D=\frac{1}{2} \times \rho \times \mathrm{v}^{2} \times S \times C D
$$

Dimana:

$p \quad:$ kerapatan udara $\left(\mathrm{Kg} / \mathrm{m}^{3}\right)$

$\mathrm{v}: \operatorname{kecepatan}(\mathrm{m} / \mathrm{s})$

$\mathrm{S}$ : luas surface $\left(\mathrm{m}^{2}\right)$

$\mathrm{C}_{\mathrm{D}}$ : coefisien drag 


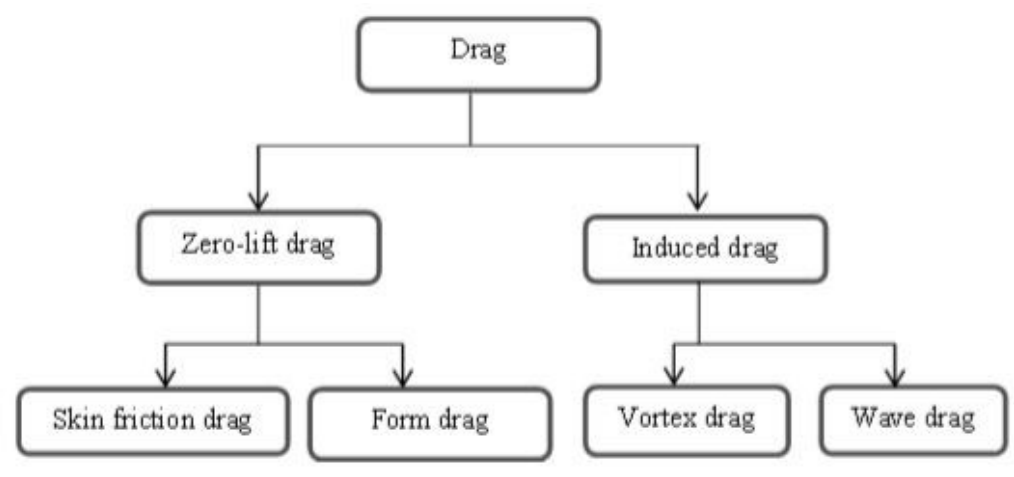

Gambar 2. Berbagai Bentuk Drag

Induced Drag adalah gaya yang dihasilkan dari gaya angkat pada wing. Aliran udara di atas permukaan wing cenderung mengalir ke arah fuselage dikarenakan memiliki lebih sedikit tekanan udara dibandingkan area sekitarnya. Aliran udara di bawah wing cenderung mengalir menjauhi fuselage dikarenakan memiliki tekanan udara lebih besar dibandingkan area sekitarnya. Dua aliran bertemu pada trailing edge wing menciptakan turbulensi dan drag. Tekanan udara tinggi dari bagian bawah wing cenderung mengaliran disekitar wing tip menggantikan udara bertekanan rendah di atas wing. Vortisitas pada wing tip menyebabkan $\operatorname{drag}[6][7]$.
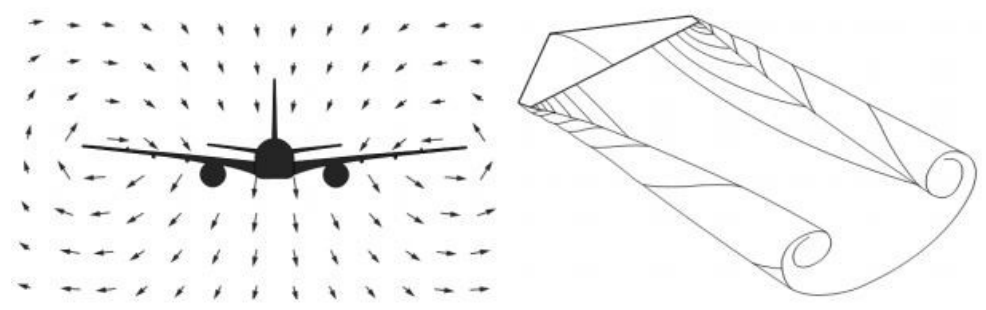

Gambar 3 Induced drag

Adapun langkah - langkah untuk mencari nilai induced drag antara lain:

$$
\begin{aligned}
& D_{i}=q \cdot \mathrm{S} \cdot C_{D i} \\
& C_{D i}=\frac{C_{L}^{2}}{\pi \cdot A R \cdot e} \\
& A R=\frac{b^{2}}{A} \\
& A R_{\text {effective }}=1,2 \times A R \\
& q=\frac{1}{2} \cdot \rho \cdot V^{2} \\
& e=1,78\left\{1-\left(0,045 \times \text { aspek ratio }^{0,56}\right)\right\}-0,69
\end{aligned}
$$

Dimana:

$\mathrm{D}_{\mathrm{i}} \quad$ : induced drag

$\mathrm{C}_{\mathrm{L}} \quad$ : Koefisisen Lift

$\mathrm{C}_{\mathrm{Di}} \quad$ : Koefisisen Induced Drag

AR : Aspek Ratio 


$\begin{array}{ll}\text { AReffective } & : \text { Aspek Ratio wing tip } \\ \mathrm{q} & : \text { dynamic pressure }\left(\mathrm{Kg} / \mathrm{m}^{2} \mathrm{~s}\right) \\ \mathrm{b} & : \text { Wing Span }(\mathrm{m}) \\ \mathrm{A} & : \text { luas sayap }\left(\mathrm{m}^{2}\right) \\ \mathrm{e} & : \text { Faktor Efisiensi Oswald }\end{array}$

Wing tip devices menjadi struktur kecil memeainkan peran penting dalam mengurangi induced drag di pesawat. Banyak jenis wing tip devices yang telah dirancang dan signifikan mengurangi induced drag. Salah satu tujuan utama karya tesis ini adalah untuk mempelajari tentang desain wing tip devices dan kontribusi dalam mengurangi induced drag [8] [9]. Adapun jenis wing tip devices yaitu blended wing tip devices, spiroid wing tip devices, dan lain-lain..
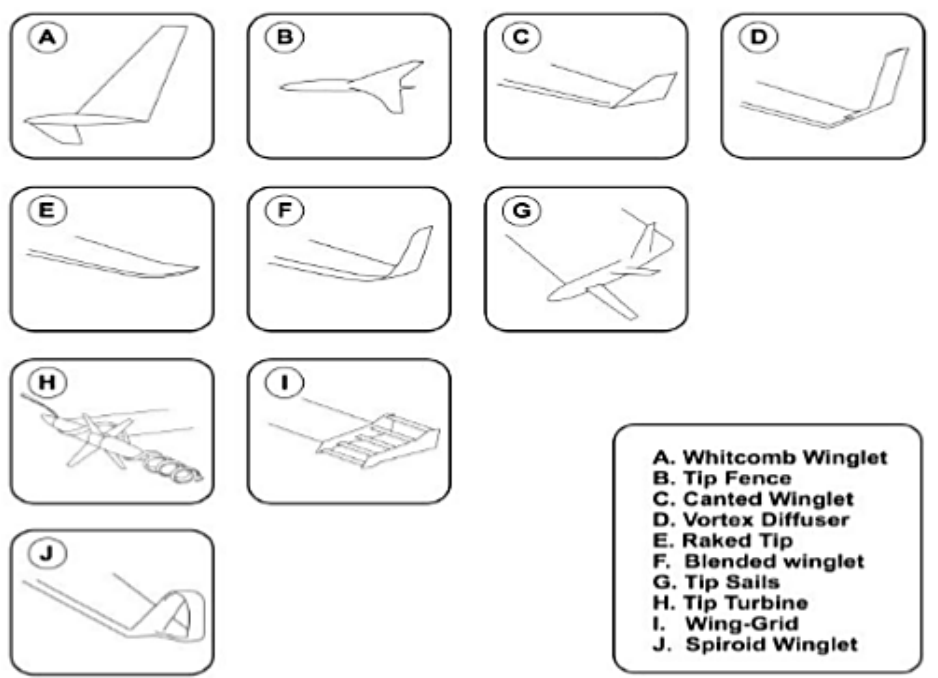

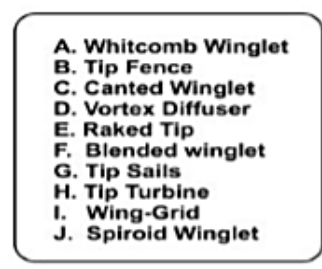

Gambar 4 Tipe Wing tip devices dan Wing Tip Device (M. Barrios dan P. Herman, hal; 10)

Computational Fluid Dynamic (CFD) adalah cabang ilmu mekanika fluida yang menggunakan algoritma dan metode numerik untuk memecahkan dan menganalisis masalah aliran udara fluida, yang meliputi transfer massa, perpindahan panas, perpindahan fasa, reaksi kimia dan lain-lain. CFD dapat melakukan simulasi perilaku aliran udara didalam suatu domain dengan beberapa kondisi batas tertentu dan memberikan solusi aliran yang diinginkan dengan bantuan komputer. Langkah-langkah utama dalam pemodelan CFD terbagi menjadi tiga tahapan yaitu:

a. Pre-Processing Pada langkah pertama ini biasanya pendeskripsian geometri dilakukan.

Lalu, domain fluida yang digunakan juga harus ditentukan. Setelahnya, domain fluida dibagi menjadi segmen-segmen kecil atau yang biasanya dikenal sebagai langkah mesh generation.

b. Solver Setelah masalah teridentifikasi, properti fluida, model fisik dan kondisi batas harus ditentukan untuk selanjutnya diproses oleh komputer. Pada proses solver ini, komputer Menggunakan governing equation sesuai dengan masalah aliran yang dianalisis.

Post-processing hasil dari proses solver dapat dianalisis pada proses ini. Hasil-hasil tersebut dapat ditampilkan dengan metode seperti plot kontur aliran, plot vektor, streamline, hingga representasi grafis dari aliran. Selain itu data-data kuantitatif seperti gaya angka, gaya hambat, dan momen aerodinamika juga dapat dihitung. 


\section{Metode Penelitian}

Metode penelitian yang digunakan adalah metode numerik computational fluid dynamic dengan software ANSYS CFX. Adapun propetis udara yang digunakannya sebagai berikut

Tabel 1. Properties Udara

\begin{tabular}{|l|c|c|}
\hline \multicolumn{1}{|c|}{ Keterangan } & Nilai & Satuan \\
\hline Kecepatan Cruise & 27,7778 & $\mathrm{~m} / \mathrm{s}$ \\
\hline Ketinggian & 914,4 & $\mathrm{~m}$ \\
\hline Masa Jenis & 1,121 & $\mathrm{~kg} / \mathrm{m}^{3}$ \\
\hline Tekanan & 90812 & $\mathrm{~N} / \mathrm{m}^{2}$ \\
\hline Model Turbulensi & \multicolumn{2}{|c|}{ K-Epsilon } \\
\hline
\end{tabular}

Pada proses pembuatan geometri wingtip devices UAV kali ini menggunakan software Computational Aided Designe (CAD) CATIA V5R20. Geometri wingtip yang digunakan sebagai objek penelitian kali ini ada dua bentuk yaitu blended winglet dan whitcomb winglet. Didalam penentuan dimensi objek penelitian ini merujuk penelitian yang dilakukan oleh $\mathrm{P}$. Panagiotou dkk, 2014.

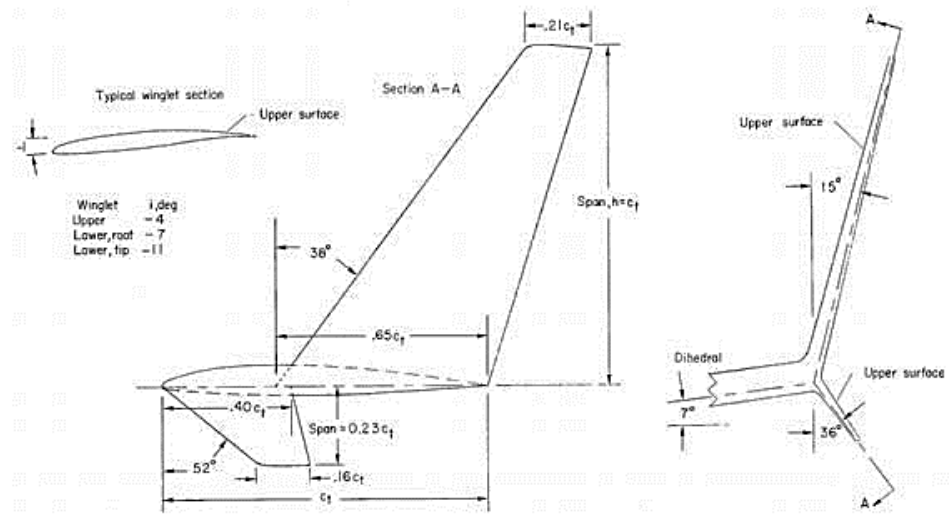

Gambar 5. Dimensi Whitcomb Winglet

Penelitian ini hanya akan melakakukan perbandingan antara wing tanpa canted winglet dan dengan canted winglet . pada prosesnya wing digambar cukup setengah dari wingspan, dikarenakan untuk mempercepat dan memudahkan proses penelitian. Berikut adalah spesifikasi geometri wing LSU-05.

Tabel 2. Geometri Wing

\begin{tabular}{|l|c|c|}
\hline \multicolumn{1}{|c|}{ Keterangan } & Nilai & Satuan \\
\hline Wing Span & 5,5 & $\mathrm{~m}$ \\
\hline Luas Sayap & 3,246 & $\mathrm{~m}$ \\
\hline Chord Root & 0,714 & $\mathrm{~m}$ \\
\hline Chord Tip & 0,44 & $\mathrm{~m}$ \\
\hline Taper Ratio & \multicolumn{2}{|c|}{0,616} \\
\hline Aspect Ratio & \multicolumn{2}{|c|}{9,32} \\
\hline Twist Angle & 0 & $\mathrm{deg}$ \\
\hline Swept Angle & 0 & $\mathrm{deg}$ \\
\hline Angle Of Incident & 3 & $\mathrm{deg}$ \\
\hline Airfoil & \multicolumn{2}{|c|}{ Naca 4415 } \\
\hline
\end{tabular}




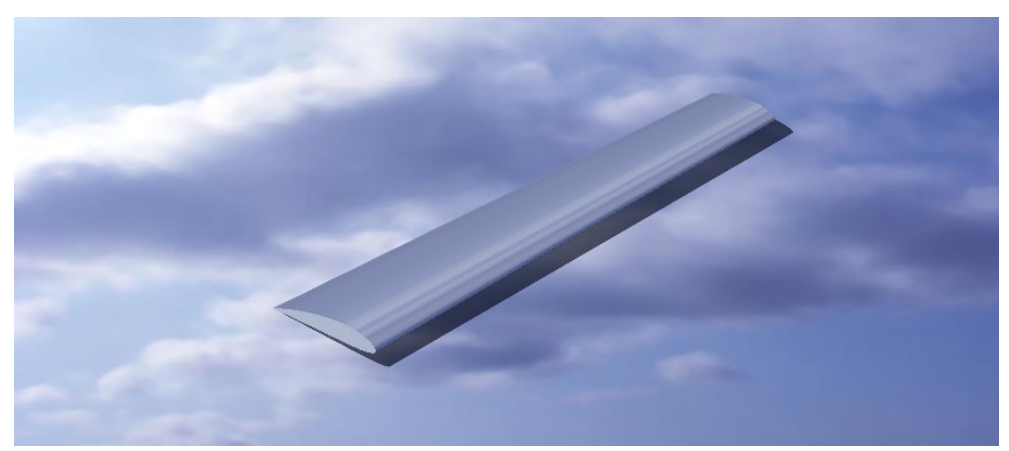

Gambar 6. Geometri Wing Tanpa Canted Winglet

Tabel 3.Geometri canted winglet

\begin{tabular}{|l|c|c|}
\hline \multicolumn{1}{|c|}{ KETERANGAN } & NILAI & SATUAN \\
\hline Span $\mathrm{H}$ & 440 & $\mathrm{~mm}$ \\
\hline $\mathbf{C}_{\mathrm{t}}$ Canted Winglet & 92,4 & $\mathrm{~mm}$ \\
\hline Cant Angle & 50 & Deg \\
\hline
\end{tabular}

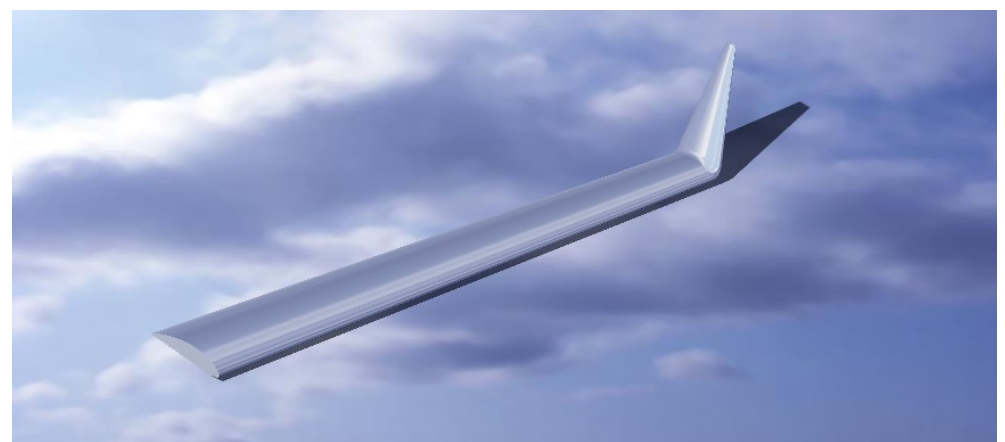

Gambar 7. Geometri Wing Dengan Canted Wingle

Setelah kedua geometri dibuat lalu disimpan dengan format STP, dilanjutkan ke proses studi konvergensi. Namun, sebelum melakukan studi konvergensi terlebih dahulu membuat control volume yang berfungsi untuk membatasi atau mengkunci batas ruang lingkup pengujian suatu benda dengan ukuran panjang kedepan $5 \mathrm{x}$ design, panjang kebelakang $10 \mathrm{x}$ design, tingginya $5 \mathrm{x}$ design.

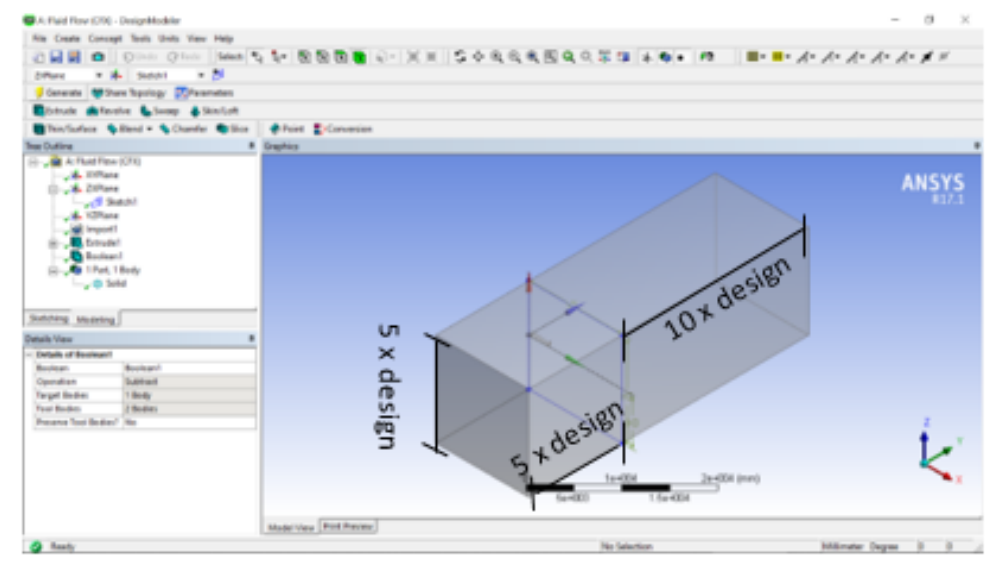

Gambar 8. Control Volume 
Studi konvergensi meshing adalah proses pengkajian diskritisasi suatu benda dalam hal ini wing tanpa dan dengan canted winglet yang hasil dari simulasinya mengerah kepada satu titik pertemuan. Didalam melakukan pemodelan diskritisasi suatu objek semakin halus atau kecil elemennya maka hasil yang akan didapatkan akurat.

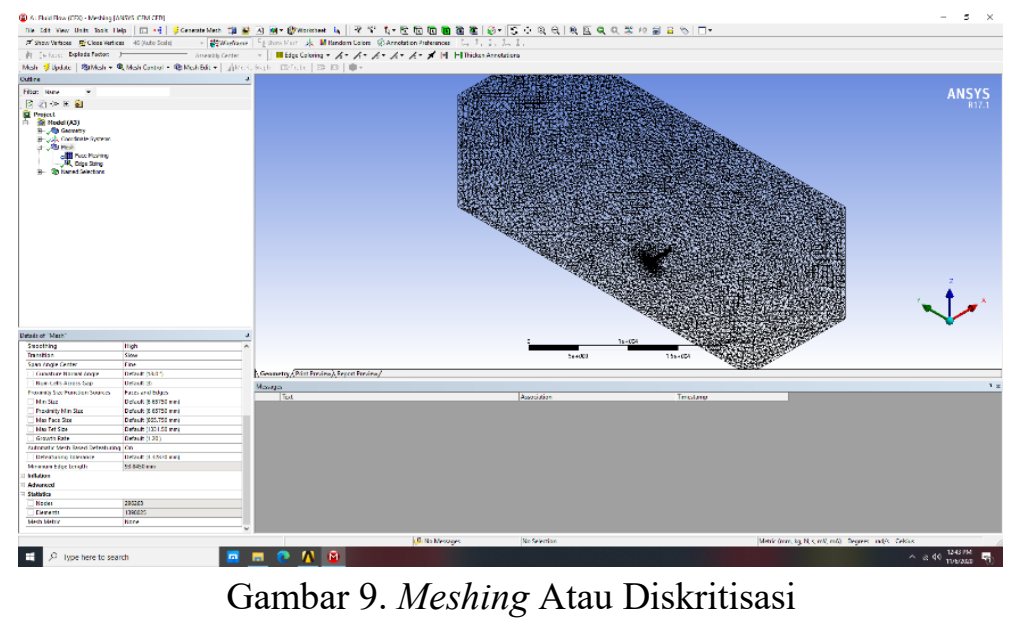

Namun, karena jaringannya dibuat halus atau kecil maka otomatis waktu komputasi meningkat dan spec komputer yang digunakan harus semakin besar. Berdasarkan informasi di atas untuk mengetahui jumlah elemen yang baik selaras dengan akurasi dan spec komputer seefisien mungkin salah satu caranya adalah dengan melakukan konvergensi meshing. Adapun hasil yang didapatkan didalam studi konvergensi meshing, berikut tabel konvergensinya.

Tabel 3. Studi Konvergensi Mesh

\begin{tabular}{|c|c|c|c|c|}
\hline No & Objek & NOE & $\mathbf{C}_{\mathbf{L}}$ & $C_{D}$ \\
\hline 1 & \multirow{5}{*}{$\begin{array}{c}\text { Wing tanpa } \\
\text { canted winglet }\end{array}$} & 373.100 & 0,7082280 & 0,0441731 \\
\hline 2 & & 1.035 .953 & 0,7664690 & 0,0405027 \\
\hline 3 & & 1.049 .337 & 0,8032013 & 0,0424889 \\
\hline 4 & & 1.610 .572 & 0,8071102 & 0,0413925 \\
\hline 5 & & 5.977 .221 & 0,8130446 & 0,0391347 \\
\hline
\end{tabular}

Berdasarkan di atas dapat dikatakan bahwa simulasi tersebut sudah konvergen dikarenakan semakin tinggi number of element hasilnya sudah mengarah ke satu titik pertemuan dan sudah sesuai dengan literature yang sudah disebutkan di atas. Dalam hal ini dengan jumlah elemen sebelumnya yaitu 1.610.572 dinaikan ke 5.977.221 nilai $\mathrm{C}_{\mathrm{L}}$ yang didapatkan tidak jauh berbeda dari 0,8071102 ke 0,8130446 . Data hasil studi konvergensi yang digunakan pada proses simulasi canted winglet adalah number of element (NOE) 1.049.337. 


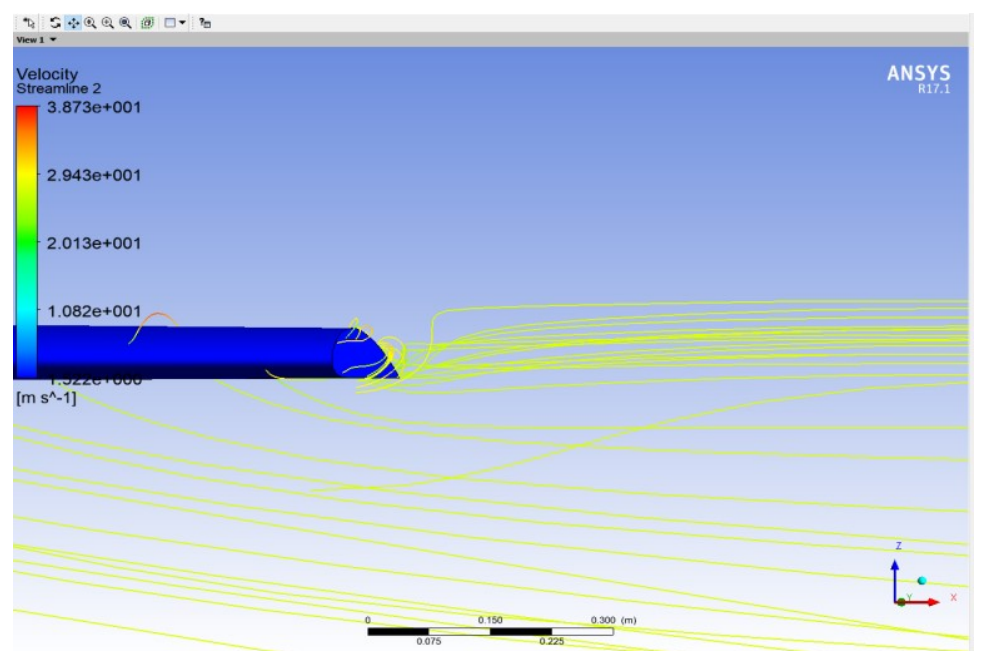

Gambar 10. Streamline Wing tanpa Canted Winnglet

\section{Hasil Dan Analisis}

Pada simulasi canted winglet langkah - langkahnya sama seperti yang dilakukan sebelum - sebelumnya namun, yang membedakannya hanya parameter meshing sesuai dengan hasil studi konvergensi. Parameter meshing yang digunakan adalah untuk proximity size function sources sebesar $5 \mathrm{~mm}$, face sizing sebesar $5 \mathrm{~mm}$, size function (proximaity and curvature), relevance center (fine), smoothing (high). Berikut hasil dari simulasi canted winglet dengan cant angle $50 \mathrm{deg}$.

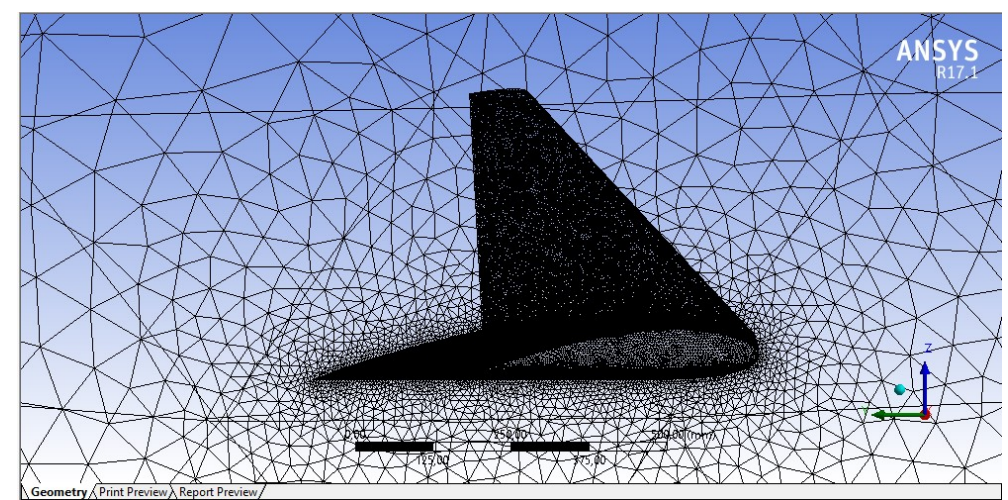

Gambar 11. Meshing Canted winglet

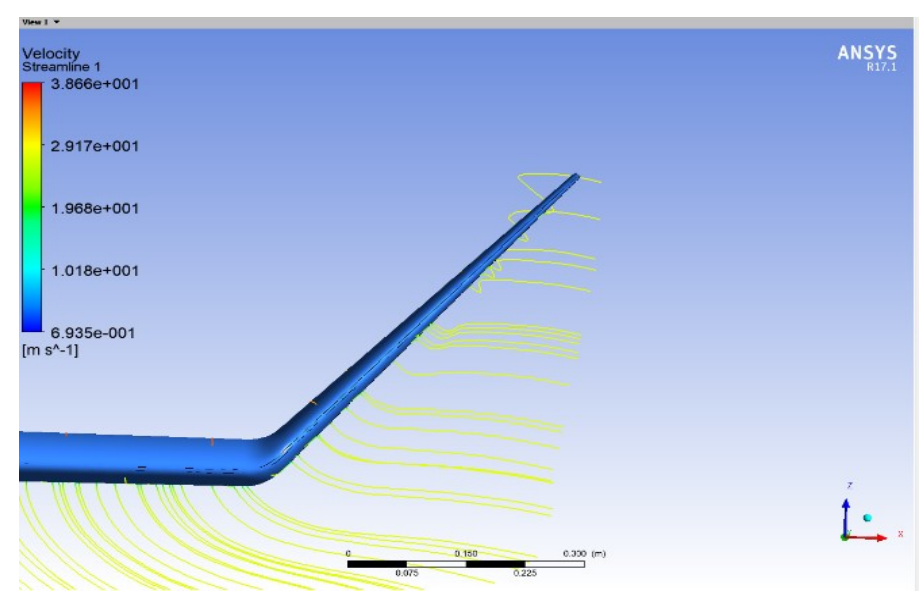

Gambar 12. streamline Canted Winglet 
Berdasarkan hasil simulasi objek canted winglet didapatkan nilai lift force dan drag forcenya sebesar 1003,86 N dan 46,4403 N. Dari hasil tersebut digabungkan dengan hasil simulasi wing tanpa canted winglet untuk mengetahui seberapa besar pengaruhnya terhadap nilai induced dragnya berikut datanya.

Tabel 4. Nilai Lift Force Dan Drag Force Wing Tanpa canted winglet Dan Canted winglet

\begin{tabular}{|c|l|c|c|c|}
\hline No & \multicolumn{1}{|c|}{ Nama Objek } & Lift Force & Drag Force & Satuan \\
\hline 1 & Wing Tanpa canted winglet & 955,275 & 50,5335 & $\mathrm{~N}$ \\
\hline 2 & Canted winglet & 1003,86 & 46,4403 & $\mathrm{~N}$ \\
\hline
\end{tabular}

Untuk mendapatkan nilai induced drag terlebih dahulu mencari nilai $\mathrm{C}_{\mathrm{L}}, \mathrm{AR}_{\text {effective, }}$, $\mathrm{e}_{\text {canted Winglet }}, \mathrm{q}, \mathrm{C}_{\mathrm{Di}}$, dan $\mathrm{C}_{\mathrm{Di}}$ (Canted Wunglet) berikut datanya:

Tabel 5. Nilai $C_{L}, C_{L} / C_{D}, A R, e, q, C_{D i}$, Dan $D_{i}$

\begin{tabular}{|c|c|c|c|c|c|c|c|c|}
\hline $\mathbf{N o}$ & Objek & $\mathbf{C}_{\mathbf{L}}$ & $\mathbf{C}_{\mathbf{L}} / \mathbf{C}_{\mathbf{D}}$ & $\mathbf{A R}$ & $\mathbf{e}$ & $\begin{array}{c}\mathbf{q} \\
\mathbf{k g}\end{array}$ & $\mathbf{C}_{\mathbf{D i}}$ & $\begin{array}{c}\mathbf{D}_{\mathbf{i}} \\
\mathbf{m} \mathbf{s}^{\mathbf{2}}\end{array}$ \\
\hline 1 & $\begin{array}{c}\text { Wing Tanpa } \\
\text { Canted Winglet }\end{array}$ & $\begin{array}{c}0,80 \\
3\end{array}$ & $\begin{array}{c}18,90 \\
4\end{array}$ & $\begin{array}{c}9,32 \\
\mathbf{2}\end{array}$ & 0,8619 & $\begin{array}{c}432,485 \\
3\end{array}$ & $\begin{array}{c}0,025 \\
6\end{array}$ & $\begin{array}{c}30,418 \\
1\end{array}$ \\
\hline 2 & Canted Winglet & $\begin{array}{c}0,84 \\
4\end{array}$ & $\begin{array}{c}21,61 \\
6\end{array}$ & $\begin{array}{c}11,18 \\
4\end{array}$ & 0,8304 & $\begin{array}{c}432,485 \\
3\end{array}$ & $\begin{array}{c}0,024 \\
4\end{array}$ & $\begin{array}{c}29,056 \\
6\end{array}$ \\
\hline
\end{tabular}

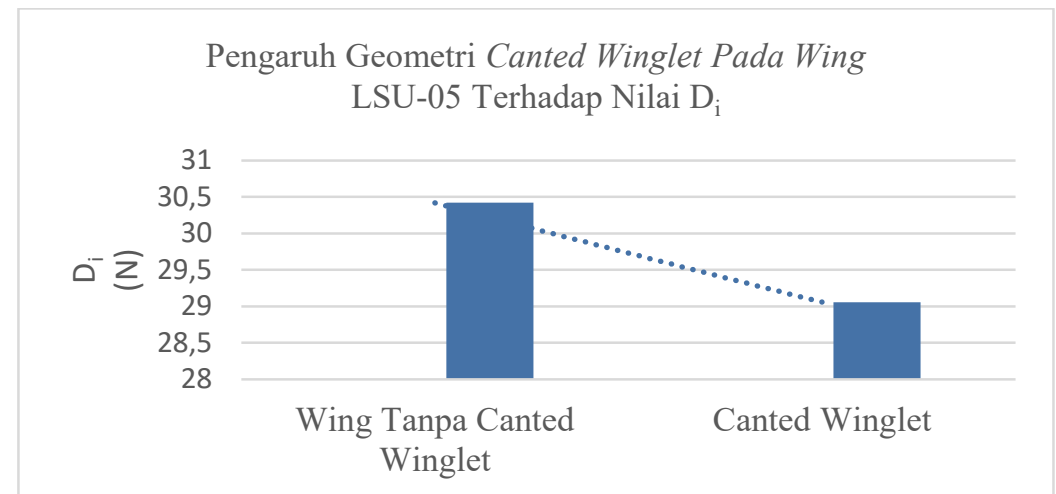

Gambar 6. Diagram Pengaruh Geometri Canted Winglet Pada Wing LSU-05 Terhadap Nilai $D_{i}$

Berdasarkan hasil simulasi sebelumnya didapatkan bahwa pengaplikasian bentuk geometri canted winglet pada profil wing UAV LSU-05 mempengaruhi nilai $C_{L} / C_{D}$ dan induced drag. Bahwa nilai $C_{L} / C_{D}$ sebelum menggunakan canted winglet sebesar 18,904 setelah diaplikasikan meningkat menjadi 21,616 sedangkan untuk nilai induced dragnya berbanding terbalik dengan $C_{L} / C_{D}$ semula $30,4181 \mathrm{~N}$ turun menjadi $29,0566 \mathrm{~N}$. Hasil tersebut sesuai dengan fungsi dari wingtip devices dalam hal ini canted winglet yaitu dapat mengurangi fenomena induced drag dan meningkatkan performa aerodinamika suatu pesawat atau UAV. Penyebab terjadinya peningkatan lift dikarenakan adanya pengaruh dari luas permukaan wing. Semakin luas permukaannya maka distribusi tekanan yang terjadi di bawah wing meningkat atau dapat dikatakan peningkatan nilai lift berbanding lurus dengan luasan wing. Hal tersebut dapat dilihat pada hasil dan pembahasan dari aliran udara di sekitar wing tanpa canted winglet terjadi vortek pada ujung sayap sedangkan di canted winglet fenomena vortex yang terjadi sangat minim dan dapat dikatakan bahwa apabila geometri canted winglet diaplikasikan dapat meningkatkan performa aerodinamika UAV LSU-05. 


\section{Kesimpulan}

Berdasarkan hasil dan pembahasan penelitian ini menggunakan metode numerik berbasis computational fluid dynamic yakni software ANSYS CFX maka didapatkan sebuah kesimpulan bahwasanya apa yang diharapkan sesuai dengan tujuan dari penelititan ini bahwa canted winglet berpengaruh dalam mengurangi induced drag dan meningkatkan performa aerodinamika pada profil wing UAV LSU-05. Dikarenakan penelititan ini bersifat membuktikan fungsi dari canted winglet dalam mengurangi induced drag dan meningkatkan performa aerodinamika, untuk pengembangan simulasi selanjutnya dapat dilakukan dengan memvariasikan cant angle, angle of attack, dan bentuk geometri wingtip divices yang lainnya

\section{Daftar Pustaka}

[1] A. Romadhon, B, and D. Herdiana, "Analisis CFD Karakteristik Aerodinamika Pada Sayap Pesawat LSU-05 Dengan Penambahan Vortex Generator", Jurnal Teknologi Dirgantara. Vol. 15 No. :45 -58, 2017.

[2] P. Panagiotou, P. Kaparos, K. Yakinthos, "Winglet Design and Optimization for a Male UAV Using CFD”, Aerospace Science and Technology, technology 39: 190 - 205, 2014.

[3] D. P. Raymer, "Aircraft Design: A Conceptual Approach", 1992.

[4] CAE Oxford Aviation Academy, "Principles of Flight ATPL Ground Training", 2014.

[5] McCormick dkk, "Aerodynamics, Aeronautics, and Flight Mechanics", 1979.

[6] A. I. Gölcük dkk, "Winglet Design and Analysis for Low-Altitude Solar Powered UAV", Int. J. Sustainable Aviation, Vol. 3, No. 1, 2017.

[7] K. A. Al Sidairi dan G. R. Rameshkumar, "Desain of Winglet device for aircraft", International Journal of Multidisciplinary Sciences and Engineering, Vol. 7, No. 1, 2016.

[8] Da Lyu, Baowei Song, Guang Pan, Zhiming Yuan, and Jian Li, "Winglet effect on hydrodynamic performance and trajectory of a blended-wing-body underwater glider", Ocean Engineering 188 (2019) 106303.

[9] I. Hanif, G. Jatisukamto, A. A. An Nafi, "Pengaruh Sudut Tekuk (Cant) Winglet Menggunakan Airfoil Naca 2215 Pada Aerodinamika Sayap Pesawat", Jurnal ROTOR, Edisi Khusus No. 3, Desember 2017.

[10] M. Barrios dan P. Herman, "Reducing Drag by Modifying the Winglet Design", The Philippine Physics Society Physics Fair, Cebu. ResearchGate. 2017.

[11] S. Rajendran, "Design of Parametric Winglets and Wing tip devices - A Conceptual Design Approach”, 2012. 